\title{
ÉTICA PURA E SITUAÇÕES MOTIVACIONAIS: O SUJEITO MORAL EM HUSSERL
}

\author{
Marcelo Fabri \\ Universidade Federal de Santa Maria
}

\begin{abstract}
The paper examines the phenomenological concept of pure ethics in Husserl's thought. The formal laws, by which this ethics has its validation, must be "filled" with the contingent matter of motivational situations. The contingencies of factual life are necessary to universalize the duty. That is the reason by which, in phenomenological sense, pure ethics must be completed by a material ethics, considering, necessarily, the self realization and self determination of the human being.
\end{abstract}

Keywords: Pure ethics, motivational situations, practical reason, phenomenological ethics.

Resumo: 0 artigo examina o conceito husserliano de ética pura mostrando que as leis formais, que fundam esta ética, só podem ter força moral na medida em que forem "preenchidas" pela matéria contingente das situações motivacionais. Nesse sentido, sem as contingências da vida factual, o dever não poderia alcançar universalização. Eis por que, em sentido fenomenológico, a ética pura deve ser complementada por uma ética material, levando em conta, necessariamente, a autorrealização e a autodeterminação do sujeito humano concreto.

Palavras-chave: Ética pura, situações motivacionais, razão prática, ética fenomenológica.

A ética husserliana se caracteriza pela retomada do conceito de a priori em assuntos morais, mas isso não significa deixar de lado os aspectos sensível, afetivo e espiritual do ser humano concreto. Husserl pretende salvar a incondicionalidade do imperativo categórico sem esquecer as situações motivacionais em que um sujeito julga, avalia, sente, delibera etc. sempre em sua ligação ao mundo e, principalmente, aos outros seres humanos. $\mathrm{Na}$ perspectiva husserliana, toda ética que não ultrapasse a dimensão egoísta e 
temporal das valorações e das ações culmina com o ceticismo moral. Por isso, é preciso compreender que a busca humana de realização ou de sentido é inseparável de uma autêntica práxis racional, pautada pelas ideias de dever, de autonomia e de liberdade. Mas o grande desafio de uma abordagem fenomenológica da ética será mostrar que as leis formais ou analíticas, próprias da lógica, são absolutamente carentes da matéria que deverá preenchê-las. Ou seja, na ausência do concreto das situações motivacionais, nenhuma idealidade teria valor real para o sujeito ético, ou ainda, sem as contingências da vida factual, o dever não poderia universalizar-se garantindo, com isso, a busca de autodeterminação e auto-realização do sujeito moral.

\section{Lógica e ética em meio a interesses teóricos e práticos}

Sempre que Husserl inicia sua discussão sobre lógica e sobre ética, ele sublinha os propósitos práticos que marcaram a origem de ambas as disciplinas. A lógica surgiu como disciplina técnica do pensamento judicativo, e tinha a função de guiar o pensamento em sua procura pela verdade. A ética, por sua vez, era a disciplina técnica do querer e do agir, e possuía um domínio muito mais vasto que o da lógica. Por quê? Porque a racionalidade prática encontra-se presente em todas as disciplinas técnicas possíveis (estratégia, arte de governar, medicina, etc.). O querer e o valorar implicam sempre a relação entre os fins que buscamos e as consequências de nossas buscas (Cf. HUSSERL, 2009 b, §1, p. 4).

Do ponto de vista fenomenológico, a ideia de correção preside não só às proposições teóricas, mas também às proposições práticas. Com efeito, é com base nestas últimas que agimos e valoramos no decorrer da vida. No entanto, a normatividade presente nas proposições práticas vai além das operações puramente lógicas do pensamento. Mais do que o correto julgar, é a questão da vida concreta que se encontra em questão. No agir e no valorar estamos implicados nas contingências das situações humanas reais, que não se deixam apreender nunca por uma atividade de pensamento comprometida apenas com a verdade e a falsidade das proposições. Por conseguinte, no plano prático, trata-se de perguntar se os fins que busco atingir são legítimos ou não, se eles devem ou não ser buscados. Tal pergunta vale tanto para as questões técnicas ligadas a uma profissão quanto para o indivíduo em geral, às voltas com a busca de uma orientação ou o sentido de sua vida. 
Eis por que, segundo Husserl, importa saber se há leis normativas de ordem superior que podem ser utilizadas pela vontade, a fim de se decidir sobre o justo, o legítimo e o melhor para cada situação. Husserl se refere a uma disciplina normativa prática superior, que estaria em condições de fornecer os princípios universais capazes de orientar a vida humana em sentido moral. É assim que o agir poderá refletir o máximo possível a ideia de uma vida boa que, desde os gregos antigos, vem desafiando a reflexão sobre a consciência moral no Ocidente (Cf. HUSSERL, 2009 b, §1, p. 5). Por outro lado, a ética é a disciplina do agir justo. Ela é teórica e prática a uma só vez, implicando a pessoa como um todo, pois é o sujeito pessoal que pode ou não passar pela vida como quem decide não só neste ou naquele caso particular, mas, sobretudo, com vistas à unidade ou coerência de sua existência. Daí a pergunta: se o problema é o sujeito pessoal às voltas com os desafios práticos da existência (individual e coletiva), por que falar em ética pura?

\section{Que entender por ética pura?}

Toda discussão teórica sobre a razão prática implica uma saída do domínio exclusivo dos conteúdos e da esfera particular dos bens para alcançar o nível lógico-formal acerca dos princípios éticos. (Cf. HUSSERL, 2009 b, §2, p. 12). Para refutar as teses relativistas e psicologistas, Husserl não abre mão de uma análise rigorosa do conhecimento humano, inclusive do conhecimento relativo ao agir. Assim, além das disciplinas técnicas ou práticas (pedagogia, jurisprudência, medicina, etc.) é preciso reconhecer a necessidade das ciências puramente teóricas, que não se definem por nenhuma disciplina técnica, isto é, por uma disciplina cujos fins são práticos. Tomemos, por exemplo, um arquiteto com seu manual de arquitetura. Por mais que este profissional esteja orientado para a realização prática de um monumento, ele deverá utilizar conhecimentos teóricos advindos de outras áreas do saber, tais como a matemática, a física, a estética, as quais, no caso, são disciplinas puramente teóricas. Ou seja, ao lado dos interesses práticos de uma ciência, devem estar os interesses puramente teóricos do conhecimento. Não é difícil perceber o quanto Husserl se aproxima, neste ponto, de Aristóteles. (Cf. ARISTÓTELES, 2006, VI, 1026a 25-30). O que caracteriza o interesse teórico é o amor e a busca da verdade, numa palavra, é a unidade possível de uma teoria universal e racional (Cf. HUSSERL, 2009 b, §3, p. 17). 
Consideremos o exemplo de um mestre de obras. Este profissional estará preocupado com uma construção específica, voltado para a realização concreta de um edifício. As proposições teóricas implícitas em seus conhecimentos são voltadas para a aplicação e, por conseguinte, direcionadas para o âmbito técnico de sua profissão. Mas tal só é possível porque todas as proposições teóricas podem, a priori, ser reconsideradas em sentido prático (Cf. HUSSERL, 2009 b, §4, p. 21), isto é, podem assumir uma função prática. Por este motivo, o contrário também será verdadeiro, a saber, "toda proposição prática pode ser convertida em sentido teorético" (Ibid.). Um pedagogo que atua profissionalmente, com fins e meios definidos, pode, eventualmente, refletir teoricamente sobre o que faz e, em especial, sobre os fundamentos de sua prática.

Eis por que as disciplinas práticas não se bastam a si mesmas. Elas aspiram a uma Ciência diretriz, a uma doutrina da ciência. Para Husserl, toda disciplina normativa e toda disciplina prática fundam-se sobre uma ou mais disciplinas teóricas (HUSSERL, 2005, Vol. I, §14). As disciplinas teóricas fundamentam as disciplinas normativas e práticas, pois toda proposição exprime a ideia de uma relação de proporção entre a norma e aquilo que é regulado normativamente, isto é, uma relação entre a condição e o condicionado. No caso da ética, pode-se dizer o seguinte. A proposição normativa inclui a proposição teórica. Vejamos um exemplo. A proposição "um A deve ser B" inclui a proposição teórica: "Somente um A que seja B possui a qualidade C (bom)”. Esta segunda proposição é nova, ou seja, é uma proposição eminentemente teórica, não contendo mais a ideia de normatividade. Consequentemente, relações teóricas se escondem por trás das proposições das ciências normativas, ou seja, toda ciência normativa requer o conhecimento de certas verdades não-normativas (Cf. HUSSERL, 2005, Vol. I, §16). A ética tem, de fato, um caráter prático, mas não se pode esquecer que sua fundação é teórica. As práticas humanas são sempre situadas empírica e historicamente, mas as ações e as valorações nem por isso deixam de ser fundadas. As atitudes de valoração, por exemplo, devem estar fundadas sobre uma teoria dos valores (Cf. HUSSERL, 2009 b, § 4, p. 24).

\section{Contra o biologismo e o ceticismo éticos}

Se a filosofia assume o modelo de ciência teórica por excelência (Ciência da Verdade), a lógica sempre poderá ultrapassar sua condição prática 
ou técnica graças a uma fundamentação teórica supra-empírica. O método é conhecido: trata-se de uma atitude ficcional ou imaginativa, aquela mesma que os matemáticos puros realizam (Cf. HUSSERL, 2006, §70). O olhar deixa-se desviar das realidades empiricamente reais para poder visar puras possibilidades ou idealidades.

No caso da ética, vale também este método? Husserl mostra que ações e valorações, mesmo que essencialmente ligadas à dimensão factual ou contingente da existência humana, não impedem que se possa falar de uma ética pura ou a priori, ao lado de uma lógica pura ou a priori. Nos atos simples de sentimento e da vontade, encontram-se conteúdos que não se reduzem aos atos que lhes deram origem. Assim:

Os fundamentos teóricos mais essenciais da tecnologia (ética enquanto disciplina prática) residem não na psicologia das funções do conhecimento e das 'funções afetivas' (Gemutsfunktionen), mas muito antes em leis e teorias a priori que são chamadas, conforme ao seu sentido próprio, a funcionar como normas racionais para todos os juízos éticos e lógicos, ou ainda, como as estrelas-guia para qualquer práxis racional que seja (HUSSERL, 2009 a, §2, p. 82-83).

Temos, então, uma analogia entre razão prática e razão teórica, graças à qual se chega à ideia de uma ética pura capaz, segundo Husserl, de vencer a luta contra o empirismo ético, entendido como psicologismo e biologismo. Com efeito, se conceitos tais como bem e mal, justo e injusto, racional e irracional etc. não fossem mais do que expressões da estrutura biológica da natureza humana, implícitas no percurso histórico e nas formas culturais da humanidade, então Hume teve razão ao pensar que a questão dos fundamentos da ética não é uma questão abstrata, mas, sim, factual. Para Hume, somente o método experimental, que deduz máximas gerais a partir da comparação de casos particulares, poderia ser o guia seguro em tal investigação (Cf. HUME, 2004, p. 231). Husserl reage dizendo que, se isso fosse verdadeiro, o desenvolvimento de uma função de consciência moral (Gewissensfunktion) seria apenas o resultado de uma utilidade biológica da espécie humana.

Daí a pergunta: julgar teoricamente de modo útil é suficiente para garantir a racionalidade? Ou ainda: pensar a ética como condicionada pela utilidade biológica pode garantir a racionalidade de uma ação? Para Husserl, 
a validade prática é tão fundamental quanto a validade teórica. O reconhecimento teórico de que algo é verdadeiro implica, no campo prático, que algo seja reconhecido como um bem (valoração positiva) e que se busque a sua realização prática (ato da vontade). O não-bem, por sua vez, é algo incorreto, irracional e privado de valor. Husserl entende que, em todo agir, é uma norma absoluta que se torna juiz. A vontade tende a um fim, ela quer assumir a universal direção para o bem.

Ver com evidência o verdadeiro equivale, pelo menos no momento da evidência, a tomá-lo (setzen) por verdadeiro, e desse modo julgá-lo como correto. Ver com evidência plena e total o bem prático ou tê-lo claramente diante dos olhos como objeto de um mandamento significa, ao menos no momento da evidência, voltar-se para ele querendo-o (Cf. HUSSERL, 2009 a, §3, p. 86-87).

\section{A correlação noese-noema no campo prático}

A ética pura não é, portanto, indiferente ao papel do sentimento na vida real dos indivíduos. Segundo Husserl, o sentir é determinante para o comportamento prático dos seres humanos. Sem o influxo do sentimento, os conceitos de bem e de mal, de virtude e de dever, etc. perderiam todo o seu sentido. Em fenomenologia, o ser humano é descrito sempre como consciência que quer isto ou aquilo, que tende a algo desta ou daquela maneira, que age deste ou daquele modo, e assim por diante. A esse respeito, os moralistas do sentimento têm razão. Como, então, responder ao ceticismo? Diante do sentimento subjetivo de prazer, onde está o lugar do dever? Não é verdade que o gosto não deve ser discutido? Como é possível preservar o sentimento como um valor positivo salvaguardando, ao mesmo tempo, a validade objetiva da decisão, da ação, da valoração? Por outro lado, também perguntamos: uma vez que as "verdades morais" implicam o sentimento, como garantir a validade das ações e das valorações sem se cair numa forma de racionalismo ético que afirma que a origem dos conceitos morais encontra-se no puro intelecto? O próprio Husserl parece assumir tal racionalismo ao afirmar: 
Assim como toda verdade teorética, na matemática ou em outra ciência exata, é única para qualquer ser racional em geral, inclusive para Deus, e na medida em que isso implica a compreensão evidente de que um ser racional deve concordar necessariamente com a de outro ser racional, assim devem ser as coisas também para a verdade moral (HUSSERL, 2009 a, $\S 32$, p. 146).

Retomemos, então, o argumento. Para Husserl, é forçoso reconhecer que as proposições éticas são proposições judicativas como quaisquer outras, pois linguisticamente expressam uma verdade que lhes pertence. Expressam, além disso, normatividade, um dever incondicional, como se cada um devesse comportar-se de certo modo, em uma dada situação. Mas os sentimentos devem ser considerados como parte fundamental da racionalidade prática. $\mathrm{Na}$ esfera prática, não se pode prescindir de um contributo do movimento afetivo da consciência. No entanto, os atos da consciência, mesmo aqueles mais carregados de emotividade, devem ser examinados em relação a seu correlato objetivo.

Uma vivência judicativa sempre possui um correlato objetivo (o julgado enquanto tal ou noema), que pode ser tomado em seu modo próprio de doação, isto é, como um sentido ou aquilo que é julgado enquanto tal. O sentido noemático, ligado a um modo de doação, é o invariante ou eidos de um percurso temporal e intencional de uma consciência. Consequentemente, um mesmo núcleo noemático pode ser o conteúdo de diferentes atos: um "estar certo de algo", um "supor algo" um "duvidar", etc. O núcleo noemático nunca está sozinho, uma vez que ele depende dos atos subjetivos que o toma por "um possível”, "um evidente", "um duvidoso", etc. (Cf. HUSSERL, 2006, § 94, p. 215).

O mesmo vale para a esfera da vontade e dos sentimentos. O sentir, o desejar e o agir são atos que também estarão dotados de sentidos noemáticos, segundo seus modos de doação. Um objeto (ou situação) percebido pode receber, além do juízo predicativo, uma dimensão de valor. Ele pode assumir aquilo que Husserl chama a forma de objeto-valor (ele recebe uma propriedadevalor). Trata-se de uma nova camada objetiva, que se edifica sobre a camada objetiva anterior. Nas palavras de Husserl: "A propriedade-valor abriga igualmente a propriedade coisa e, além dela, a valência” (HUSSERL, 2006, §95, p. 219). No caso da vontade, pode-se dizer que na base das posições volitivas sempre se encontram as tomadas de posição valorativas. No querer, algo 
sempre é intencionado como um "visado pelo querer", isto é, como aquilo que fora intencionado como "um assim deve ser".

Ora, uma vez que também na esfera prática é necessário reconhecer a correlação noese-noema, ou seja, a relação dos atos intencionais com seus conteúdos objetivos, não se pode esquecer que a reflexão lógicoepistemológica sobre a verdade do juízo é muito diferente da busca de validade para uma valoração ou uma ação. Um juízo moral não é o juízo frio de um processo matemático. $\mathrm{O}$ sentimento encontra-se ligado necessariamente a ele. Surge, então, o problema: se o desafio teórico independe do sentimento de prazer e desprazer que temos ao realizar as operações ou cálculos, facilitando a compreensão do saber lógico como um conhecimento puro ou a priori, como defender que as vivências de prazer também podem ser consideradas a partir de um saber a priori?

A fenomenologia não se contenta com questões de fato no que se refere aos princípios. Uma tomada de posição empírica poderá ser "suspensa" metodicamente, sendo considerada como puro fenômeno, isto é, em sua correlação noese-noema. Eis por que a ética fenomenológica não é uma tecnologia empírica, mas ciência a priori da razão prática e dos correlatos desta razão (Cf. HUSSERL, 2009 b, §14, p. 62). Tal ciência deve mostrar não somente a validade de sua proposta, mas também a essência dos contra-sensos que minam a possibilidade de uma práxis racional.

\section{Crítica ao hedonismo e idealidade dos valores}

Com os recursos do método fenomenológico, Husserl pretende "neutralizar" a tese central até mesmo dos hedonistas, examinando-a criticamente. Que afirma o hedonista? Que nenhum ser humano concebível poderia tender diretamente a alguma coisa que não fosse o prazer (Cf. HUSSERL, 2009 b, §15, p. 64). O prazer seria aquilo que os seres humanos buscam em tudo o que fazem. Mas para Husserl importa notar que a tese hedonista não é uma proposição empírica, mas, sim, uma argumentação a priori, que prescinde da própria vivência psicológica e factual que deu origem à referida tese.

Se um sujeito tende a algo que lhe falta (deseja), este algo vem representado como um valor. Desejo um livro. Sinto sua falta. Procuro ardentemente satisfazer o desejo que tenho até realizá-lo. Temos, então, dois momentos: a) a intenção desiderativa; b) o preenchimento da intenção 
(consciência de realização). O hedonista, afirma Husserl, simplesmente confunde o valorar com o valor, ou seja, mistura o ato com o seu correlato objetivo (no caso, o ter prazer com algo e o algo prazeroso). Se o prazer é um ato (um momento subjetivo), o objeto é, ao contrário, um valor, ou seja, é algo objetivo. O sentir é subjetivo, mas o valor, enquanto objeto, não o é (Cf. HUSSERL, 2009 b, §15, p. 67). Mas, eis o problema: dizer que os valores dependem sempre de uma proposta subjetiva, de uma apreciação individual ou coletiva, não significa afirmar que tudo poderá ser valioso, inclusive valores opostos?

$\mathrm{Na}$ perspectiva husserliana, há valores tão transitórios que não merecem uma atenção especial de nossa parte. Para um fumante compulsivo, um cigarro é um valor objetivo, a despeito dos males que causa e mesmo do prazer que terá ao fumar. Ora, diante deste tipo de valor (real), há os assim chamados valores ideais, caracterizados como supra-temporais ou eternos, tais como a ciência, a filosofia, a verdade, etc. Um objeto lógico-ideal pode, pois, ser fruído como um valor objetivo, admirado por todos os indivíduos que o consideram, numa palavra, é um valor potencialmente apto a ser admirado (Cf. HUSSERL, 2009 b, §15, p. 68). A esse respeito, Husserl afirma:

Toda obra de arte é, autenticamente, segundo o seu sentido, um valor ideal, muito embora se manifeste empiricamente e possua, por assim dizer, o seu corpo empírico real, com o qual certamente aparece e sem o qual não poderia aparecer (HUSSERL, 2009 b, §16, p. 71).

Se assim é para a arte, o será também para a filosofia e a ciência, as quais, por meio de teorias e proposições, buscam o valor de verdade que lhes confere sentido. Os valores possuem validade lógico-ideal, isto é, são objetos que possuem idealidade e, deste modo, adquirem a condição de supratemporalidade. $\mathrm{O}$ valor, explica Husserl, não é a vivência subjetiva que um sujeito possui, mas aquilo que, no objeto, é experimentado ou apreciado por este sujeito (Cf. HUSSERL, 2009 b, §16, p. 73). Mas isso resolve o problema da ética? Decididamente, não, pois, além a idealidade ou supra-temporalidade de certos valores, é preciso enfrentar o problema da busca do bem em meio às situações concretas da vida. Como se dá a relação entre a validade lógicoideal dos valores e a busca do bem, nas situações temporais e contingentes da existência? 


\section{Situações motivacionais e valoração}

Brentano, mestre respeitado de Husserl, afirmara que o bem em sentido forte é o bem em si, ou seja, é aquele que deve, do mesmo modo que a verdade, ser incondicional. Reconhecemos um bem ou o bem não pelo amor puro e simples que possuímos em nós, mas, sim, porque tal objeto é digno de ser amado. "Do mesmo modo que a correção e a evidência do juízo, a correção e o caráter superior da atividade do sentimento dependem, assim e pelas mesmas razões, do bem, ao passo que o amor daquilo que é mal é, por si mesmo, mau" (BRENTANO, 2003, p. 66). Nesse sentido, os atos de sentimento serão bons quando forem justos e, além disso, quando forem seguidos de prazer ou contentamento. Exemplos de correção formal são abundantes tanto em Brentano quanto em Husserl. Certo, a existência de um bem é preferível à existência de um mal, e isso a despeito do conteúdo considerado. Do mesmo modo, um bem isolado é melhor que o mesmo bem misturado a um mal, assim como a existência conjunta de um bem e de um mal é melhor que a simples existência de um mal. (Cf. HUSSERL, 2009 a, $\S 12$, p. 175).

De nossa parte, perguntamos: como determinar ou atingir o bem ou o melhor nas situações frágeis e contingentes da vida? Nos casos mais dramáticos da realidade difícil, o ideal (Husserl) e a evidência do melhor (Brentano) não bastam. Nas escolhas e nas valorações nós nos deparamos com distintas situações motivacionais.

Em sentido lógico-analítico, bom e não-bom são predicados que se excluem. A e não-A não podem ser o mesmo. Mas, na esfera axiológica, as coisas se passam de outro modo. Predicados de valor positivos e negativos se excluem somente se for dada a igualdade da situação motivacional (Cf. HUSSERL, 2009 a, §11, p. 164). Dito de outro modo, o princípio formal não pode, por si só, produzir a matéria. Relativismo moral? Primado do sentimento sobre a razão? Melhor seria dizer: possibilidade de que o sentimento seja trazido ao universalismo da razão. Por conseguinte, se é verdade que a razão prática implica o dever, é fundamental não esquecermos que todo dever é relativo a uma situação motivacional. Assim:

Para Husserl a decisão, a escolha é sempre ligada a uma situação particular, a um contexto com respeito ao qual qualquer um faria a mesma valoração, a qual será, por isso, universal (CENTI, 2004, p. 303). 
Uma vez que não possui a força auto-impositiva da forma (ética kantiana), a ética husserliana não apresenta a priori a decisão única para toda situação contingente. Somente tendo-se em vista as diferentes situações podese chegar a uma melhor. A matéria do ato valorativo é, então, fundamental. Escolher o melhor diante das várias possibilidades de bens existentes é imperativo categórico, mas "o melhor é eventualmente plurívoco" (HUSSERL, 2009 a, §18, p. 234). Ora, se existem bens que podemos escolher, é incorreto não realizar algum deles. É um dever escolher um deles, embora seja sempre uma escolha que se verifica na precariedade de uma contingência. Escolher o melhor entre os bens possíveis é um dever, mas o alargamento do domínio prático sempre pode apresentar um "melhor" capaz de absorver o anterior (Cf. Ibid., p. 235). Daí poder-se dizer que nenhuma situação motivacional seja fechada. A ética pertence necessariamente à dimensão temporal da vida. Para Centi, se é verdade que o bem não pode ser atingido unicamente com a lógica formal, não se pode esquecer que o bem não é casualmente relativo. O que importa é reconhecer o ato que o intenciona. Neste ato, chama-se matéria o elemento contingente e múltiplo, aquele que depende do tempo e de particulares circunstâncias culturais. A avaliação crítica do ato chama-se qualidade. É um procedimento lógico e crítico em que vários atos interagem até darem origem a um conteúdo que não é mais contingente como a matéria. Só então se chega a um significado eticamente válido, isto é, a um valor ou a um bem (Cf. CENTI, 2004, p. 306).

Assim, antes de ser uma qualidade da situação ou do sujeito, "bom" é algo que só se dá por meio do juízo formulado na valoração. Ou ainda: o predicado "bom" será válido quando houver um conteúdo universalizável em situações concretas. A valoração extrai aquilo que é específico de uma situação, mas a intencionalidade se dá como interação de atos e reflexões, e é isso que estrutura as diversas matérias como conteúdos. Extrai-se, então, o específico de uma situação, vale dizer, intenciona-se esta situação em sua concretude, juntamente com aquilo que é próprio dela (Cf. CENTI, 2004, p. 312). Eis por que, diferentemente de Kant, não é unicamente a universalidade que importa, mas, sim, a universalidade de um conteúdo. Universalidade significa, então, que um conteúdo foi julgado e reconhecido como sendo válido ou universalizável. Ora, não se chega a isso sem os atos emotivos, sem as valorações e sem os atos do juízo (Cf. CENTI, 2004, p. 315).

Valorar implica, portanto, confronto, uma interação da razão que valora com a razão que julga. É preciso buscar, mediante a reflexão, o 
máximo grau de universalização do valor. Além dos valores supra-temporais (filosofia, ciência, verdade, etc.) conquistados ao longo do processo de autoreflexão da humanidade europeia, importa compreender que, nas situações contingentes da vida, os valores serão o resultado de um processo avaliativo permanente, melhor dizendo, de um processo de ponderação reflexiva. Para Husserl, toda ocorrência na esfera emotiva é um possível objeto de apreensão teórica. A reflexão deve tornar visíveis os nexos que valem independentemente da própria reflexão. A correção dos atos de valoração é imprescindível para que a vontade esteja dotada de correção.

\section{Vontade em sentido fenomenológico}

Que é o querer? Como descrever fenomenologicamente os atos volitivos? Há dois aspectos em questão. O primeiro diz respeito à aplicação de regras formais. Qualquer sujeito que, em dada situação, agisse de modo a negar qualquer generalização ligada ao agir estaria negando a racionalidade prática (cf. HUSSERL, 2009 a, §19, p. 226). O justo categoricamente exigido é: Faça o melhor entre todos os bens possíveis (Cf. Ibid., p. 225). Ora, não se decide formalmente o que é bom, assim como não se atinge o verdadeiro apenas com a lógica formal. No entanto, pode-se afirmar que o bem e o melhor excluem a relatividade contingente. "Nós agimos com correção a partir do momento em que um expectador imparcial qualquer, colocando-se em nosso lugar, deveria aprovar nossa ação" (Ibid., p. 227).

O segundo aspecto diz respeito ao caráter pessoal do agir. Em nossas ações, encontram-se objetivos, projetos de vida, etc. O querer se funda sobre a representação daquilo que deve ser realizado. Se é verdade que o valor motiva o querer, não se pode esquecer que o querer implica a necessidade da ação. Como assim? É que, em sentido fenomenológico, o querer se dirige a uma individualidade real. O querer é um ato de conferir significado ao fazer, numa palavra, é uma aspiração ao bem. É na ação, e somente nela, que o querer se realiza temporalmente, passando da intenção ao preenchimento, numa espécie de fazer criador. Nas palavras de Husserl:

Enquanto certeza de vontade, a vontade põe, para a consciência, o futuro. Confere ao futuro unicamente a certeza de ser. De algum modo, a consciência não está dizendo: “Assim será, e por esta razão eu quero", mas, sim: "Uma vez 
que eu o quero, isto será". Em outros termos, a vontade pronuncia seu "que isto seja" criador (2009 a, §15, p. 191).

Chegados a este ponto, é preciso atentar para o seguinte. A relação da ética pura com a vida concreta ou situações motivacionais remete, necessariamente, à vida do sujeito moral sob a forma de auto-reflexão ou autodeterminação. Dito de outra maneira, o sujeito moral é aquele que vive de tal modo que, em suas valorações e ações, está sempre aprovando ou desaprovando seu próprio comportamento. Por meio de uma valoração autoreflexiva, o Eu se determina a si mesmo. À ideia de um Eu moral pertence a motivação essencial de querer a si mesmo sob a forma de um Eu que aspira ao bem, um Eu que se dirige a si mesmo (Cf. HUSSERL, 2009 b, §34, p. 158). $\mathrm{Na}$ medida em que se põe como Eu, o sujeito moral husserliano se pensa como agente racional em busca do bem, renovando-se de modo contínuo e permanente. Este sujeito está em "constante e ininterrupta auto-educação, é o eu que quer melhorar-se, transformar-se (a si mesmo como Eu) a tal ponto que, enquanto Eu ético, pode ser eo ipso somente um "Eu-que-quer-o-bem" (Ibid., p. 159).

Vale lembrar, no entanto, que essa auto-avaliação permanente não pode resumir-se a um ato solitário ou solipsista de um sujeito reflexivo. É toda a vida comunitária que se encontra em questão. Os outros são também sujeitos morais em processo de autodeterminação podendo, por isso, tornar possível a ética em sentido social. Nesse sentido, a comunidade pode realizar, de modo análogo ao eu pessoal, o seu querer sob a forma de vida de renovação, dando a si mesma a forma de uma autêntica humanidade (Cf. HUSSERL, 1999, p. 3 e ss.).

\section{O sujeito moral em Husserl}

Voltemos ao Eu moral. Este vive numa espécie de tensão: intenciona (aspira) o bem antecipando, ao mesmo tempo, a realização deste mesmo bem. Uma vez atingido, o fim lhe trará satisfação ou auto-satisfação. Trata-se, como afirmou uma intérprete da ética husserliana, de um hedonismo não egoísta, pois a satisfação de si, no prazer da realização, é a condição para toda satisfação ulterior (Cf. BIANCHI, 1999, p. 143 e ss.). O sujeito ético luta permanentemente contra suas tendências, procurando superar o lado passivo de sua existência. Assim, ele se afirma como agente livre e avesso a toda acomodação ou renúncia 
da liberdade. Um sujeito solidário, portanto, que pensa nas dores da humanidade, comprometendo-se com a diminuição dessa dor.

Por outro lado, e além do contexto da vida concreta, o sujeito moral pode ser tomado como ideia, mesmo que ele não deixe de ser um eu pessoal e concreto. Tomá-lo como ideia, significa visá-lo a partir do ideal de um verdadeiro $\mathrm{Eu}$, que vive autenticamente a partir da verdade de suas valorações (Cf. HUSSERL, 2009 b, §34, p. 161). Husserl afirma que o ideal de homem prático é o ideal de um ser humano racional, uma espécie de duplo espiritual de um si mesmo (Cf. HUSSERL, 1999, p. 42). Trata-se de um ente ideal que trazemos, a priori, em nós. A forma de vida categoricamente requerida é, pois, aquela em que o Eu se justifica diante de si mesmo, vivendo em atos que devem ser julgados de modo absoluto.

Mas, aqui, é preciso cuidado. É na medida em que agimos, sentimos, imaginamos, decidimos, lutamos etc. que podemos visar à ideia de um ser humano sob a forma de Eu verdadeiro, isto é, como um Eu que não é, mas que deve ser. Em outros termos, diante da vida real, está a verdadeira e autêntica vida. Esta não é vivida pura e simplesmente, pois é a vida que deveria ser vivida (Cf. HUSSERL, 2009 b, §47, p. 236. Diante das situações concretas da vida, o Eu pode ganhar-se ou perder-se. Para ganhar a si mesmo, deve querer transformar-se num Eu verdadeiro, recriando-se e renovando-se de modo infindável. O imperativo deste sujeito moral é o de regular sua vida de maneira autônoma e evidente, vale dizer, regular esta vida de acordo com o sentido do dever. Mas esta busca do Eu verdadeiro e autêntico se desdobra igualmente para a comunidade humana, isto é, pensa-se como ideia de uma autêntica humanitas. Ora, nem mesmo o hedonismo pode prescindir desta busca, embora ele o faça de modo inadequado e com fins equivocados. Que é, para Husserl, o sujeito ético? Nenhum outro senão aquele que se tornou sujeito e objeto da própria aspiração, lutando renovadamente e interminavelmente pela clareza, pela verdade e pela justiça (Cf. HUSSERL, 1999, p. 44).

\section{Referências bibliográficas}

ARISTÓTELES. Metafísica. Trad. Edson Bini, São Paulo: EDIPRO, 2006. BIANCHI, I. Etica Husserliana. Studi sui manoscritti inediti degli anni 19201934. Milano: Franco Angeli, 1999. 
BRENTANO, F. L'origine de la connaissance morale (suivi de La doctrine du jugement correct). Trad. Marc de Launay e Jean-Claude Gens. Paris: Gallimard, 2003.

CENTI, B./GIGLIOTTI, G.(Orgs.). Fenomenologia della ragion pratica. Napoli: Bibliopolis, 2004.

CENTI, B. "Il concetto di valore nelle Lezione di ética (1914)". In: CENTI, B./GIGLIOTTI, G.(Orgs.). Fenomenologia della ragion pratica, Napoli: Bibliopolis, 2004 (p. 255-325).

HUME, D. Uma investigação sobre os princípios da moral. Trad. José Oscar de Almeida Marques, São Paulo: UNESP, 2004.

HUSSERL, E. L'idea di Europa. Cinque saggi sul rinnovamento. Trad. Corrado Sinigaglia. Milano: Raffaello Cortina Editore, 1999. - Ricerche logiche. Trad. Giovanni Piana, Milano: Net, 2005.

- Idéias para uma fenomenologia pura e para uma filosofia fenomenológica. Trad. Márcio Suzuki, Aparecida: Artes e Letras, 2006. . Leçons sur l'éthique et la théorie de la valeur (1908-1914). Trad. Philippe Ducat, Patrick Lang e Carlos lobo, Paris: PUF, 2009a. - Introduzione all'etica (1920-1924). Trad.Nicola Zippel. RomaBari: Laterza, 2009 b.

MELLE, U. "Husserls personalistische Ethik". In: CENTI, B./GIGLIOTTI, G.(Orgs.) Fenomenologia della ragion pratica, Napoli: Bibliopolis, 2004, p. 327-355. 